\title{
Explaining the link between agentivity and non-culminating causation *
}

\author{
Fabienne Martin \\ University of Stuttgart
}

\begin{abstract}
This paper offers an account for why, cross-linguistically, denying the whole change of state encoded by causative verbs is easier with agent than with causer subjects. It does so by extending the theory of the progressive developed in Varasdi $(2014 a, b)$ to non-culminating readings of causative verbs, not only in progressive but also in perfective sentences. It additionally sustains two claims about the difference between agentive and nonagentive ongoing causation events: Only the former (a) can in principle start before their potential effects start and (b) are systematically 'indicative' of these potential effects.
\end{abstract}

Keywords: agentivity, agent vs. causer subjects, causative verbs, non-culminating accomplishments, defeasible causatives, sublexical modality, progressive

\section{Introduction}

This paper focuses on the way the agentivity of the subject's referent affects the availability of so-called non-culminating construals of causative verbs. For perfective sentences, two types of non-culminating readings for accomplishments have been distinguished. Under what Demirdache \& Martin (2015) call the 'zero-CoS' reading (of which the 'failed attempt' reading of Tatevosov \& Ivanov 2009 is the agentive subtype), the change of state $(\mathrm{CoS})$ encoded by the predicate does not occur to any positive degree, see the Halkomelem (Salish language) example (1), from Gerdts 2008, cited in Jacobs 2011: 25.

* Károly Varasdi has played a crucial role in the elaboration of this paper through very substantial feedback and comments on its previous versions. This work has also greatly benefited from an ongoing collaboration with Hamida Demirdache on the link between non-culmination and agentivity cross-linguistically. Many thanks too to Christopher Piñón for his constructive suggestions and careful proofreading, to the SALT reviewers and audience as well as to Pier Marco Bertinetto, Hamida Demirdache, Anamaria Fălăuş, Nicolas Guilliot, Zsófia Gyarmathy, Hans Kamp, David Oshima, Orin Percus, Tillmann Pross, Florian Schäfer and Lucas Tual for their inspiring feedback, and to the editorial team of this volume for their valuable work. None of them is responsible for my mistakes or misunderstandings. This work is part of the project B5 of the SFB 732 hosted by the University of Stuttgart and financed by the Deutsche Forschungsgemeinschaft, as well as the MOSCA project (Spanish Ministerio de Economía y Competitividad FFI2012-34170, 2013-2016, PI E. Castroviejo).

(C)2015 Martin 
Explaining the link between agentivity and non-culminating causation
(1)

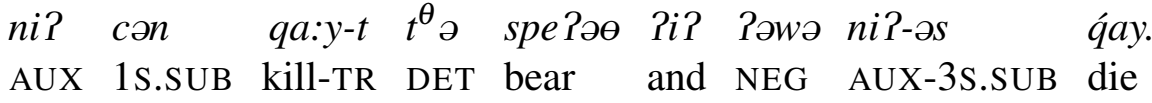
'I killed the bear but it didn't die.'

Under the 'partial-CoS' reading (of which Tatevosov \& Ivanov's 2009 partial success reading is the agentive subtype), only a proper part of the CoS occurs, or the CoS satisfies the predicate encoded by the verb to a degree $0<d<1$ on the relevant scale, see the French and Mandarin examples (2) and (3) (from Demirdache \& Martin 2015).

(2) Ce séjour à la mer l'a soigné, quoiqu'il

This stay at the sea him=has treated although=he

n'ait pas fini de guérir.

NEG=have-3S NEG finish to cure

'This stay at the sea 'treated' him, although he hasn't finished recovering.'

(3) Tāmen hǔ̌ le wò-de iPhone, dàn méi wánquán

3PL destroy PERF 1S-DE iPhone but NEG completely

huĭ-diáo.

destroy-DROP

'They destroyed my iPhone, but not thoroughly.'

This paper aims to provide an account for why, cross-linguistically, the zero-CoS reading is easier to get when the subject's referent is a 'full' agent than when it is a causer (inanimate):

(4) Agent Control Hypothesis (weak version): Zero-CoS

non-culminating construals require the predicate's external argument to be associated with agenthood properties. (Demirdache \& Martin 2015)

Many (genetically unrelated) languages seem to confirm this correlation (see e.g., Jacobs 2011 on Salish languages, Demirdache \& Martin 2015 on Mandarin Chinese, Tsujimura 2003: 297-298 on Japanese and Travis 2010: 213 on Malagasy). On the other hand, the partial-CoS reading generally does not seem to require agenthood on the part of the subject. ${ }^{1}$

Among other tasks, the relevant properties for zero-CoS non-culmination still need

1 The 'weak' version of this hypothesis might not suffice for Salish and perhaps Mandarin Chinese, see Jacobs 2011 and Liu in prep.

Verbs like eat are here analyzed as monoeventive (manner) verbs. Since they do not encode a $\mathrm{CoS}$ besides the action denoted, the zero- or partial-CoS non-culminating reading are by definition excluded for these verbs. However, it is interesting to note that crosslinguistically, many manner 
to be identified. We know that full agentivity is sufficient but not necessary to get them, since in particular contexts, the zero-CoS reading is available when the subject is a causer or is not fully agentive (Martin \& Schäfer 2012; Copley \& Wolff 2014).

For Germanic and Romance, many authors — Ryle (1949), Oehrle (1976), Haïk (1989), Hacquard (2006), Ruwet (1995), Levin \& Rappaport Hovav (2014) a.o. - have identified verbs that confirm the correlation between agenthood and the zero-CoS reading. Take e.g., (5) vs. (6-7) and (8) vs. (9): ${ }^{2}$

$$
\text { Dr Li m'a soigné, mais je n'ai pas guéri du tout. }
$$
dr Li me=has treated but I NEG=has NEG cured at all 'Dr. Li treated me, but I didn't recover at all.'

(6) Ce séjour chez ma soeur m'a soigné, \#mais je n'ai this stay at my sister me=has treated but I NEG=has pas guéri du tout.

NEG cured at all

'This stay at my sister's 'treated' me, but I didn't recover at all.'

(7) Ce traitement placebo l'a soigné, \#et pourtant, elle this treatment placebo her=has treated and nevertheless she n'a pas guéri du tout.

$\mathrm{NEG}=$ has cured NEG at all.

'This placebo treatment 'treated' her, and nevertheless, she didn't recover at all. $^{3}$

(8) Ils l'ont réparé mais ça ne fonctionne toujours pas. they it=have repaired but this NEG works still NEG 'They repaired it but it still doesn't work.'

(9) Le choc l'a réparé \#mais ça marche toujours pas. the shock it=has repaired but this works still NEG 'The shock repaired it but it still doesn't work.'

verbs that have a non-culminating telic reading are strongly agentive (cf. e.g. eat, drink or read). This prima facie also speaks in favour of a link between agentivity and non-culmination. However, this may simply be a consequence of the fact that manner verbs are very often agentive, as noted e.g. in Rappaport Hovav \& Levin 2008: 33.

2 Note that contrary to English treat, the French verb soigner is a causative verb, as confirmed by the fact that it has a (reflexively marked) anticausative reading.

3 Note that (7) is worse than (6), which can in fact be rescued in the appropriate context, see e.g., (33) in section 5 . 
Explaining the link between agentivity and non-culminating causation

Following Martin \& Schäfer (to appear), I call these verbs 'defeasible causatives'. This label is justified by the fact that most of these verbs display a causative morphosyntax on both readings, although they do not entail a CoS in their agentive use (which is why I assume with Martin \& Schäfer that the semantics of these verbs involves a sublexical modal component, see section 4.4. below). Relatedly, I will call 'CoS-less causation event' the causation event minus its CoS. In the examples provided, the CoS-less causation event minimally consists of the event involving the subject's referent (e.g., in (8), the action performed by the after-sales service on the Theme).

The set of causative verbs displaying the contrast varies cross-linguistically. Languages like Japanese and Mandarin Chinese allow one to deny the whole CoS even with core causative verbs like open, see the Japanese example (10) below, from Tsujimura 2003: 397-398.

\section{(10) Mado-o aketa-kedo sabituiteite akanakatta. window-ACC opened-but rusty did-not-open \\ 'I opened the window, but it didn't open because it was rusty.'}

However, there is also variation in this set of more liberal languages. For instance, Kato (2014) notes that Burmese allows non-culminating construals more easily than Japanese. There is also inter-speaker variation (and perhaps even intra-speaker hesitation) within one language; for Japanese, while Tsujimura presents (10) as unproblematic, David Oshima (p.c.) judges the same example as acceptable, but adds that it nevertheless sounds prima facie contradictory. The same feeling is triggered by French examples like (8): Although generally judged acceptable, they nevertheless sound initially contradictory and some speakers even reject them. This regular intuition about zero-CoS construals already indicates that their paraphrase with try verbs is misleading. Zero-CoS uses of causative verbs are stronger than their conative correspondents, since the latter are never problematic. ${ }^{4}$ The analysis proposed in section 4 aims to capture this difference between zero-CoS causations and tryings, too. It focuses on French, but the hope is that it can be extended to other languages as well.

\section{Extending the link to progressive sentences}

Although in Romance and Germanic languages, standard (i.e., non-defeasible) causatives like wake up do not have zero-CoS readings in perfective sentences, they

4 This is clearly a consequence of another striking and well-known difference between non-culminating construals and conative ones, namely that in absence of contrary information, the former are repeatedly said to implicate culmination, while the latter implicate non-culmination (Karttunen 1971: 353, fn. 12). 
nevertheless also confirm the link between agenthood and CoS deniability when used in progressive sentences. For instance, (12) seems to convey more strongly the inference that Ana started to wake up at reference time than (11). The contrast between (13) and (14) is similar. ${ }^{5}$

(11) I'm waking up Ana (I've already shaken her two times!), but she drank a lot; there is a good chance that it will take long before she starts to make a little step out of her sleep.

(12) The dishwasher's noise is waking up Ana, but she drank a lot; \#there is a good chance that it will take long before she starts to make a little step out of her sleep.

(13) Ana is opening the door. But it is so well stuck in the frame that there is a good chance that it will take long before it starts moving even a little bit.

(14) The wind is opening the door. \#But it is so well stuck in the frame that there is a good chance that it will take long before it starts moving even a little bit.

I argue that the contrasts in (5-9) and (11-14) have the same source and are due to two distinctive and related properties of actions. Let me illustrate the idea pursued below through (13-14). The first relevant property of actions has to do with the left boundaries of agentive vs. nonagentive causation events. Intuitively, the opening initiated by an agent described in (13) has a sharp beginning, independent from the targeted CoS: The action of opening the door starts once Ana puts her intention into practice. (In the technical terms adopted below, Ana's action sustains an opening event $e$, although $e$ is not efficacious yet.) By contrast, it is hard to see when the 'nonagentive' opening described in (14) would start if not when the door actually starts to open because of the wind. A second related distinctive property of actions concerns the information an action provides us with respect to the type of effect it aims to bring about. Observing somebody trying to open a door very often suffices to let us understand that this ongoing action is the initial proper part of a door-opening rather than of a causation event of another type. Such an action provides us with this information whenever it actually culminates in an opening or not. In fact, we perhaps even do not have to see the door itself to understand that Ana is opening the door rather than doing something else; very often, looking at the agent alone suffices to understand what is going on (think about the evocative power of actions performed by a mime on imaginary objects). In more technical terms again, Ana's action indicates its goal with regard to the set of contextual alternatives. By contrast,

5 Note that these contrasts appear in French too, although the French progressive does not have a futurate reading, as in most Romance languages, see Bertinetto 2000: 588. 
Explaining the link between agentivity and non-culminating causation

if we observe the blowing wind only, abstracting away from all other considerations, nothing in the event $e$ observed tells us that $e$ constitutes the initial part of a dooropening rather than another contextual alternative.

In this paper, I will spell out this informal idea through the analysis of the progressive by Varasdi $(2014 a, b)$. Very briefly, the claim is that the zero-CoS construal is possible in progressive and perfective sentences if and only if the CoSless causation event sustains and indicates the complete causation type denoted by the predicate, and that this is easier to achieve with an agent subject than with a causer subject. These terms, borrowed from Varasdi, will be defined more precisely below. The paper is structured as follows. Section 3 briefly summarizes the relevant aspects of Varasdi's theory of the progressive. Section 4 spells out my proposal. Section 5 shows how this proposal accounts for the data presented in the introduction.

\section{Varasdi's analysis of the progressive}

\subsection{Basic ingredients}

One of the core ideas of the analysis developed in Varasdi 2014a,b is that the progressive is in essence contrastive: The context $C$ in which a progressive sentence $\operatorname{PROG}(\phi)$ is uttered always provides (explicitly or implicitly) a set of outcome options, one of which is the $\phi$-property. The progressive operator has access to this set of relevant mutually disjoint eventuality properties $\Theta_{C}=\left\{\theta_{1}, \theta_{2}, \ldots, \phi\right\}$. A second main ingredient of Varasdi's proposal is Asher's 1992 insight that the progressive is true of an event $e$ by virtue of a certain set $\mathscr{F}$ of properties that $e$ has. Which properties? Varasdi suggests that the answer to this question lies in Gendler Szabó's 2004 observation that the progressive is generally entailed by the non-progressive: 'If Ana crossed the street, then at least for some time leading up to the moment of her reaching the other side, she was crossing the street.' If the progressive is entailed by the non-progressive, Varasdi concludes, 'then whatever makes the progressive true must be among the conditions necessary for the culmination. [...] the progressive refers to certain necessary conditions for the culmination.'

The relevant set $\mathscr{F}$ of sine qua non (Sqn) conditions divides into two subsets, namely, the indicative and sustaining conditions. Indicative conditions have to do with properties of the ongoing event that single out the event type $\phi$ encoded by the predicate of the contextually given set of alternatives. Sustaining conditions are required to sustain the development of the event toward the indicated outcome. That is, they are the conditions necessary for the event to make progress towards its culmination. Let us illustrate how the analysis works through one of Varasdi's examples. 


\subsection{Indicative and sustaining conditions in more detail}

Rick, a ganster, has three friends in different rooms of the same hotel. Bob's phone number is 3958, Tom's is 3796 and Jack's is 2241. One night, Rick tried to call a friend for help before being killed. In the situation $S$, Rick dialed '37' (in that order). The question we aim to answer is whether (15) is true in $S$.

(15) Rick was dialing Tom's phone number (when he died).

Here, the most accessible set of alternatives is $\Theta_{C}=\left\{\right.$ Rick-dial $l_{\emptyset}$-Tom's-phonenumber $=\phi$, Rick-dial $\emptyset_{\emptyset}$-Bob's-phone-number, Rick-dial $\emptyset_{\emptyset}$-Jack's-phone-number $\}$.

Clearly, the property $F$ of dialing ' 37 ' in that order singles out (indicates) the event type of dialing Tom's number from among the contextually given outcome options. Therefore, the first subset of Sqn conditions $\mathscr{F}$ is fullfilled. If the sustaining conditions - the second subset of $\mathscr{F}$ (integrity of the phone, presence of electricity, Rick's being alive, Rick's pushing the keys of the phone...) — are fulfilled too, sentence (15) is expected to be true.

Varasdi (2014b) formally defines indicative properties as in (16). Given a family $\mathscr{G}$ of mutually disjoint sets, a property $F$ is indicative of a particular set $G_{i}$ with respect to $\mathscr{G}$ if $F$ has a nonempty intersection only with this set $G_{i}$ in $\mathscr{G}$.

(16) Definition 1 (indicative properties, Varasdi 2014b).

Let $\mathscr{G}=\left\{G_{1}, G_{2}, \ldots, G_{n}\right\}$ such that $G_{i} \cap G_{j}=\emptyset$ if $i \neq j$. A property $F$ is

indicative of set $G_{i}$ with respect to the family of sets $\mathscr{G}$ if $F$ has a nonempty intersection only with $G_{i}$ in $\mathscr{G}$, i.e., if $F \cap G_{i} \neq \emptyset$, and for any $j \neq i$, $F \cap G_{j}=\emptyset$.

What if the ongoing event has no indicative property for the right outcome with respect to the contrast set? Varasdi (2014b) proposes that if an indicative link cannot possibly be established between a property of the ongoing event and one of the options in the contextual contrast set of outcomes, the sentence is infelicitous. In this perspective, he proposes to reanalyze the anomaly of Mittwoch's 1988 example (17) as a direct consequence of the fact that 'there is normally nothing about a lake that could help us single out a ten-feet rise rather than any other possible amount of rise in height.' 6

6 By contrast, imagine, for (15), an alternative situation $S$ ' where Rick dialed '3'. In $S$ ', the ongoing event also has no indicative property for the alternative 'Rick-dial $\emptyset$-Tom's-number' with respect to $\Theta$. In $S^{\prime},(15)$ is therefore false (or lacks a truth-value, see Naumann \& Piñón 1997). However, contrary to what happens in Mittwoch's example (17), dialing 3 is nevertheless 'potentially' indicative of the right alternative in that this property of the dialing event provides evidence putting us within a more restricted subset of $\Theta$ (i.e., Rick dialed either Bob's or Tom's number). According to the intuition of 
Explaining the link between agentivity and non-culminating causation

(17) \#The level of the lake was rising 10 feet (when I arrived).

Sustaining conditions associated with the progressive play a crucial role too, in that they capture the fact observed by Grano (2011) that contrary to try, the progressive requires that an event is ongoing in the external (non-mental) world of evaluation, see Grano's contrast (18) (see also a.o. Gendler Szabó 2004, Condoravdi 2009 for related considerations).

(18) a. \#John was unknowingly paralyzed and was raising his arm.

b. John was unknowingly paralyzed and tried to raise his arm.

If I try to raise my arm while paralyzed, the sustaining conditions for my arm-raising are not fullfilled; (18a) is therefore predicted to be contradictory.

\subsection{The need for facets}

Among the set of all properties of an event, only a subset singles out the outcome of the event. Observers differ in their ability to identify the various subsets of indicative properties, and consequently may differ in their judgements about the truth of the progressive sentence. Varasdi illustrates this point through Dowty's example (19). As Dowty observes, (19) is odd in a context where a coin is flipped up into the air and the odds are even.

(19) \#The coin is coming up heads/tails.

Varasdi's 2014b insight here is that different approximations of the same event (different subsets of all its properties, varying with the perspective $\pi$ at hand) may give rise to different judgments about the truth of (19). The facet $F_{\lambda}-$ a particular subset of the properties - of the flipping event which the everyday observer has access to is not indicative of the right outcome with respect to the contrast set. Therefore, the lambda onlooker is likely to find the sentence anomalous, because nothing, in the situation, singles out either the outcome 'the-coin-come $_{\emptyset}$-up-heads' or 'the-coin-come $\emptyset_{\emptyset}$-up-tails' from the (two element) set of contextually relevant outcomes. However, the very detailed facet $F_{\phi}$ of the same event to which a wellequipped physicist has access does determine the result of the flipping, and enables him to make a choice between the alternatives in the contrast set. ${ }^{7}$

my informants, there is a difference of acceptability between (15) in $S$ ', which is felicitous (although not true), and (17), which is clearly odd. This suggests that the lack of indicative properties results in infelicity only if the set of potential alternatives is not restricted into a smaller subset of alternatives.

7 See Strzalko, Grabski, Stefanski, Perlikowski \& Kapitaniak 2008, cited in Varasdi 2014b. 
I repeat Varasdi's definition of the progressive in (20) (I have to refer to Varasdi 2014 b for details). Condition 1 requires that $\mathscr{F}$ be indicative of $\phi$ within the context $C$ : In every world in which $e$ has facet $\mathscr{F}$, if $e$ develops into an event within the contrast set $\Theta_{C}$, then it develops into a $\phi$-event. Condition 2 ensures that Condition 1 is not vacuously satisfied (there must be at least one world where the event is complete). Condition 3 asserts that the bundle of properties $\mathscr{F}$ is necessary for $e$ to develop into a $\phi$-event.

(20) Definition of the progressive (Varasdi 2014b).

$M, w_{0}, C, g \models \operatorname{PROG}(\phi)(e)$ iff there is a bundle of properties $\mathscr{F}$ conjunctively true of $e$ at $w_{0}$ such that

1. for all $w \in \pi(e, \mathscr{F})$ : if $\unlhd_{w}(e) \cap R_{w}^{C} \neq \emptyset$, then $\unlhd_{w}(e) \cap R_{w}^{C} \subseteq \llbracket \phi \rrbracket_{g}^{M, w}$, and

2. for some $w \in \pi(e, \mathscr{F}): \unlhd_{w}(e) \cap R_{w}^{C} \neq \emptyset$, and

3. for all $w \notin \pi(e, \mathscr{F}): \unlhd_{w}(e) \cap \llbracket \phi \rrbracket_{g}^{M, w}=\emptyset$.

\section{The zero-CoS reading: More than a try, less than a success}

\subsection{Extending Varasdi’s analysis}

The strategy pursued here consists in extending Varasdi's analysis just presented to cover all non-culminating readings of causatives, in progressive and perfective sentences. The idea is that non-culminating causative sentences are acceptable as soon as the remaining ongoing event sustains and indicates the causation event type denoted by the predicate. In a slogan: 'Strip off the complete causation event as much as you want, as long as the remaining (initial) event component still fulfills the relevant indicative/sustaining conditions'.

Let us spell out the idea in more detail. Let $\phi$ be a causative VP (e.g., cure y, wake up $y$ ), $\psi$ the property of the $\mathrm{CoS}$ encoded by $\phi$ (e.g., y-get $\emptyset$-healthy, $y$-wake $\emptyset$-up), and $\Theta_{C}$ the contrast set $\left(\Theta_{C}=\left\{\theta_{1}, \theta_{2}, \ldots, \theta_{n}, \psi\right\}\right)$.

(21) HYP. 1. For a causative verb $\phi$ with $\psi=\operatorname{CoS}(\phi)$ to successfully describe an ongoing causation event $e$,

a. there must be a facet $\mathscr{F} \subseteq\{P \mid P(e)\}$ such that $\mathscr{F}$ indicates $\psi$ rather than any other alternative with respect to the set $\Theta_{C}$;

b. the ongoing causation event $e$ must fullfill the sustaining conditions for $e$ to culminate in a $\psi$-event.

If the activity that the subject's referent is presently engaging in - let us call it $e_{S}$ - satisfies the sustaining/indicative conditions on its own, the zero-CoS reading is 
Explaining the link between agentivity and non-culminating causation

available. If it does not, the most accessible repair consists in assuming that the ongoing causation event involves at least an initial part of the CoS. Under the assumption that an initial proper part of the $\mathrm{CoS}$ indicates and sustains a complete $\mathrm{CoS}$ of the type encoded, the ongoing causation event now satisfies the sustaining/indicative conditions. Together with some hypotheses about the difference between actions and nonagentive events (given in section 4.3), HYP. 1 will enable me to provide an account for why zero-CoS readings of causative verbs are generally easier to get with agents than with causers.

\subsection{Two modifications}

I modify Varasdi's analysis in two respects. Firstly, I only consider cases where the contrast set of alternatives contains two alternatives, the 'causally successful' one encoded by the predicate and the 'causally unsuccessful' one. For instance, for $x$ is waking up $y$, I will assume a contrast set $\Theta_{C}=\{y$-wake $\emptyset$-up, $\neg y$-wake $\emptyset$-up $\}$. A more substantial modification concerns the definition of indicative properties. In order to see why it is needed, consider again (5).

$$
\begin{aligned}
& \text { Dr Li m'a soigné, mais je n'ai pas guéri du tout. } \\
& \text { dr Li me=has treated but I NEG=has NEG cured at all } \\
& \text { 'Dr. Li treated me, but I didn't get cured at all.' }
\end{aligned}
$$

The strategy I will pursue consists in claiming that if (5) is acceptable, it is (a.o.) because the event $e_{S}$ described in (5) (the treatment) indicates my recovery with

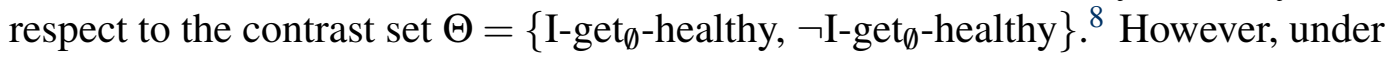
Varasdi's definition of indication in (16) (together with HYP. 1), saying that the treatment in (5) has a facet $\mathscr{F}$ indicative of my recovery with respect to $\Theta_{C}$ forces one to say that all $\mathscr{F}$-events that develop in an event in contrast set $\Theta_{C}=\left\{\right.$ I-get $_{\emptyset}$-healthy, $\neg \mathrm{I}$-get $\emptyset_{\emptyset}$-healthy $\}$ necessarily develop into 'I-get $\emptyset_{\emptyset}$-healthy'-events, which is clearly too strong. I therefore adopt a more liberal definition of indicative conditions. ${ }^{9}$ Let us call $\operatorname{Sqn}\left(\theta_{k}\right)(\mathrm{e})$ the set of properties that define, for an event $e$, the Sqn conditions for $e$ to culminate in a $\theta_{k}$-event. We will say that an event $e$ indicates the alternative $\theta_{k}$ w.r.t. $\Theta_{C}$ if $e$ actualizes significantly more Sqn conditions for $e$ to culminate in a $\theta_{k}$-event than for it to culminate in any other alternative of the contrast set.

8 By contrast, a placebo treatment does not indicate my recovery with respect to $\Theta$, which is at the source of the problem of (7).

9 This new definition was suggested to me by K. Varasdi through discussion. See Gyarmathy 2015 for other independent arguments in favour of a definition of the concept of indication less strict than the one given in Varasdi 2014b. 
(22) Definition 2 (indicative properties). Given a set of alternatives $\Theta_{C}=\left\{\theta_{1}, \theta_{2}, \ldots, \theta_{n}\right\}$ and an event $e$, the facet $\mathscr{F}$ of event $e$ indicates $\theta_{k}$ w.r.t. $\Theta_{C}$ iff $e$ realizes significantly more Sqn conditions for $e$ to culminate in $\theta_{k}$ than for it to culminate in any other alternative in $\Theta_{C}$ :

$\left|\mathscr{F} \cap \operatorname{Sqn}\left(\theta_{i}\right)(e)\right|$ is significantly bigger if $i=k$ than otherwise (i.e., if $i \neq k$ )

The idea, then, is that for the zero-CoS reading to be acceptable, the event $e_{S}$ involving the subject must actualize enough Sqn conditions to 'tilt' the contrast set in the right direction. For instance, the action $e$ of my doctor in (5) must actualize significantly more Sqn conditions for it to culminate in my recovery than Sqn conditions for it to culminate in my non-recovery, which is (hopefully) indeed the case, at least if my doctor is not a charlatan. The ongoing event $e$ must therefore be more than a try: Remember from section 1 that try does not even require an ongoing event to take place in the external world of evaluation. ${ }^{10}$ If there is no event going on, the contrast set can certainly not be tilted in the right direction. However, $e$ must also be less than a success, even partial: My doctor's action should also not actualize sufficient conditions for my recovery to be initiated (otherwise, the zero-CoS reading is by definition excluded).

\subsection{Why actions are special}

Recall from the data presented in the introduction that it is easier to deny the whole $\mathrm{CoS}$ described by a causative verb with an agentive subject than with a nonagentive one. I argue that two distinctive properties of actions compared with nonagentive events are responsible for this tendency. Firstly, actions are firstclass indicators of the agent's goal (section 4.3.1). Secondly, only agentive nonculminating causation events have clear beginning/left boundaries independently of their potential effects (section 4.3.2). These two properties of actions explain why they more systematically sustain and indicate the causation event type denoted by the predicate than nonagentive events.

Additionally, I will show that events performed by an instrument (as e.g. an alarm-clock) exhibit these two relevant properties of actions, too. I therefore sustain Alexiadou \& Schäfer's 2006 claim that instrument subjects behave as agents, not causers.

\subsubsection{Actions are first-class indicators of the agent's goal}

My first hypothesis on the specificity of agentive causation events is in (23).

10 Grano (2011) shows that try minimally picks out what he calls the 'mental action' stage of an event. 
Explaining the link between agentivity and non-culminating causation

(23) HYP. 2. Actions (including processes involving an instrument) as expressed by a causative verb $\phi$ specifying a $\operatorname{CoS}$ property $\psi$ are systematically indicative of $\psi$-CoSs.

How do I know that an ongoing event $e$ actualizes significantly more Sqn conditions for $e$ to culminate in the successful alternative rather than in the completely unsuccessful one? Arguably, identifying the bundle of properties of the ongoing event indicative of the right outcome is not always a trivial task. However, as soon as I know about the agent's intention, I do not need to grope my way very long in the two sets of Sqn conditions to find the indicative link: The agent's intention automatically enables me to single out the intended outcome among the two. One could even say that an intention put into action (i.e., intention together with an appropriate activity geared toward realizing the goal) is a proxy for the actual realization of the goal. ${ }^{11}$

Of course, one does not always have access to the agent's intention. But actions are also routinely subcategorized in terms of their causal power to bring about certain effects; a $\phi$-type of action, plan, routine, typicality structure is often associated with a $\psi$-type of outcome. For instance, seeing $x$ shaking a sleeper generally provides us with enough information to understand that $x$ is waking up the sleeper. These actional types are thus powerful indicators of the goal when the agent's intention is not overt.

On the other hand, nonagentive events neither have intentions nor plans, except when involving entities with a 'telic role' (like an alarm clock or a medical treatment, see Pustejovsky 1995). Besides, although nonagentive events are also paired with types of effects (the wind opens or closes doors, blows out candles, etc), the first members of these pairs - e.g., <wind, door-close $\emptyset>,\left\langle w i n d\right.$, candle-blow-out $\left.t_{\emptyset}\right\rangle$, etc. - are not differentiated from each other by distinctive categorial features. For instance, we do not differentiate the wind that may blow out a fire from the wind that may close a door through distinctive features: All these winds are undifferentiated for us. (By contrast, we very clearly distinguish closing-door actions from blowingout-fire actions, through typicality structures, plans, routines, etc.). As a result, when observing a nonagentive event, we are not automatically provided with an indicative link, and in some cases, we have to roam and compare sets in the jungle of Sqn conditions randomly. A problem for the zero-CoS reading arises when the indicative property is identified once it is too late and the outcome triggered: Identifying the indicative link amounts to identifying sufficient conditions for the outcome to be partially realized. This is at the source of one of the problems of (14): Once we are in a position to recognize that the wind is opening the door, it is too late for the zero-CoS reading to be still possible.

11 This point obviously relates to Naumann \& Piñón's 1997 claim that an agent's intention can make a progressive sentence true. 
Martin

\subsubsection{Actions without effects have clear beginnings}

However, the better retrievability of the indicative link with agents than with causers cannot explain everything. Take for instance (24), from Truswell 2011a, provided by a reviewer.

(24) A: (Observing the sea advancing towards a fragile-looking sandcastle, but not yet touching it): What is the sea doing?

B: \#It's destroying that sandcastle.

Very clearly, the ongoing event described in (24) is indicative of the destruction rather than the conservation of the sandcastle. And yet, "if the sea is not physically destroying the sandcastle, then we cannot claim that it is destroying the sandcastle' (Truswell 2011a: 12). ${ }^{12}$ By contrast, as Truswell observes, an agent can be more easily claimed to be destroying the sandcastle although she has not touched it yet.

My hypothesis (supported by data presented below) is that this difference is essentially due to a difference in the conceptualization of the beginning of agentive vs. nonagentive causation events. ${ }^{13}$ Agentive causation events have clear left boundaries even when not efficacious yet, because they start as soon as the agent's intention is put into action. For instance, Ana is destroying the sandcastle as soon as she puts her intention to do so into action (and as Truswell observes, this action can start before Ana touches the sandcastle). ${ }^{14}$ On the other hand, nonagentive causation events typically start once the encoded result starts, because nothing, apart from

12 As Z. Gyarmathy (p.c.) observes, Bonomi (1999: 185-186) already makes the same point about a similar example (The water is wetting the meadow). However, Bonomi does not emphasize the role of the nonagentive subject here (which is Truswell's focus).

13 Truswell's 2011a take on agentive vs. nonagentive destroy is slightly different. His claim is that agentive destroy is an accomplishment, while nonagentive destroy is an achievement (in Truswell 2011b: 101, he relatedly claims that 'a nonagentive accomplishment is a contradiction. An accomplishment is agentive, by definition, and an accomplishment with the agentivity removed becomes an achievement'). However, it is not entirely clear to me how the fact that destroy is an achievement with a causer subject explains that it is not acceptable in the context of (24). In fact, (i) below is perfect in the given context, although reach is undisputably an achievement:

i A: (Observing the sea advancing towards a fragile-looking sandcastle, but not yet touching it): What is the sea doing?

B: It's reaching our sandcastle!

Secondly, nonagentive destroy does not behave like an achievement with respect to aspectual tests (see e.g., Piñón 1997): It is acceptable with incompletion adverbials, does not force the after interpretation of in-adverbials, and does not show the same restrictions as achievements with for-adverbials (cp. The wind destroyed our tower for ten minutes with *The sea reached our castle for ten minutes). Under my proposal, both agentive and nonagentive destroy are accomplishment verbs.

14 Dowty (1977: 67) already observed that an agentive accomplishment in the progressive can be used while the 'accomplishment proper' has not started yet. He writes: 'An imperfective [standard progressive] sentence such as John is drawing a circle may be truly uttered on certain occasions 
Explaining the link between agentivity and non-culminating causation

the result, can provide an alternative left boundary to such causation events. For instance, on which ground could we claim that the sea started to destroy the castle at that precise moment $m$, if $m$ is not the moment when the sea is touching it? Relatedly, for a sentence like The sea destroyed the sandcastle in $n$ minutes, where could we start to measure time independently of the result? I reformulate this hypothesis as in (25).

(25) HYP. 3. Agentive ongoing causation events (including processes involving instruments) are ontologically independent of their effects (they come into existence with the intention or plan put into action), while nonagentive ongoing causation events ontologically depend on their effects (they come into existence once they are efficacious only).

From HYP.3, it follows that causative verbs can have a zero-CoS reading only with an agentive or instrument subject, since nonagentive causation events start once they trigger an effect.

To come back to (24), even if it is clear that the event $e_{S}$ of the sea approaching the sandcastle denoted in (24) indicates the destruction, $e_{S}$ is not part of an ongoing destruction; rather, $e_{S}$ is (part of) the event preceding the actual destruction. In this sense, $e_{S}$ does not fulfill the 'right' sustaining conditions: Since the destroying event has not started yet, it cannot be in progress (hence the oddity of (24)).

A first argument in favour of HYP. 3 involves temporal adverbials.

a. John has to wake up Ana and puts his intention into action at 10.00. At 10.15, Ana woke up.

b. $\rightarrow$ John woke up Ana in 15 minutes.

a. The dishwasher starts to run at 10.00. At 10.15, Ana woke up, and it was because of the dishwasher.

b. $\not \rightarrow$ The dishwasher woke up Ana in 15 minutes.

In the situation described in (26a), (26b) is necessarily true (if 'John' is assigned the role Agent), which is expected if the waking up initiated by an agent starts once the intention is put into action. On the other hand, in the situation described in (27a),

when no portion of a circle exists yet on paper, but when John is merely observed to be making preparations to draw (assembling compass and paper, etc.) and his intentions are known. Perhaps this use is merely 'speaking loosely', but it suggests at least a psychological tendency of humans to extend the temporal 'duration' of an accomplishment (in Vendler's sense) backward in time to include the preparations for the accomplishment proper, i.e., the direct bringing about of a result' (my italics). I believe that 'stretching' the agentive accomplishment to the left is possible with both types of non-culminating readings (in progressive and perfective sentences). On this view, this meaning extension is not imputable to the progressive. 
(27b) is not necessarily true, because the start of the dishwasher program does not provide the left boundary of the nonagentive waking up event.

Instrument subjects - subjects referring to entities $x$ whose purpose and function (i.e., telic role) is to trigger a $\mathrm{CoS}$ of the type denoted by the verb - behave exactly like agentive subjects, in that the beginning of the instrument's activity provides the left boundary of causation events as clearly as an intention-in-action does. Consequently, the instrument subject in (28) patterns with the agent subject (26), and not the causer subject (27).

(28) a. The alarm clock started to ring at 10.00. At 10.15, Ana woke up, and it was because of the alarm clock.

b. $\rightarrow$ The alarm clock woke up Ana in 15 minutes.

The second argument concerns the interpretation of adverbials like almost. As already observed in e.g., Vecchiato 2004 and Martin 2005, the counterfactual reading that almost has with agentive accomplishments seems lost with the nonagentive reading of the same verbs. For instance, while (29a) is compatible with a situation where John does not do anything, (29b) is not appropriate in a situation where nothing happened (the washing program does not even start). This is simply because in the agentive case (29a), the left boundary of the (counterfactual) waking up causation event is the left boundary of John's (counterfactual) action. On the other hand, in the nonagentive case (29b), the (counterfactual) waking up causation event does not start with the dishwasher's program. There is therefore no difference in the scope of almost; rather, the left boundary of the (counterfactual) waking up event is provided by John's action in (29a), but by the CoS in (29b). Note that again, instrument subjects pattern with agent subjects, see (29c).

a. John almost woke up Ana.

$(\checkmark$ no action)

b. The dishwasher almost woke up Ana.

c. The alarm clock almost woke up Ana.

(\#no washing event)

( $\checkmark$ no ringing event)

The same contrast arises with modals like should.

a. John should have woken up Ana.

$(\checkmark$ no action)

b. The dishwasher should have woken up Ana. (\#no washing event)

c. The alarm-clock should have woken up Ana. $\quad$ ( $\checkmark$ no ringing event)

In (30a), should can have John's action in its scope, which is expected if the (counterfactual) waking up causation event starts with the (counterfactual) trying-to-wake-up. In (30b), should does not have the whole washing in its scope: The sentence tends to presuppose that the dishwasher ran, which is expected if the (counterfactual) 
Explaining the link between agentivity and non-culminating causation

waking up causation event starts with the (counterfactual) encoded CoS rather than the washing. Again, (30c) shows that instrument subjects pattern with agent subjects.

\subsection{Source of the modality}

According to the proposal just presented, the zero- $\mathrm{CoS}$ reading of causative verbs is licensed in the same conditions in progressive and perfective sentences. However, the modal element that shifts the CoS to possible worlds is not the same in both cases. In progressive sentences with standard (non-defeasible) causatives (e.g., English wake up), the $\mathrm{CoS}$ is shifted to possible worlds by the progressive operator PROG. In perfective sentences, this job is performed by a sublexical modal component à la Koenig \& Davis (2001), see (31), at least for languages like Romance and Germanic. ${ }^{15}$ This explains why the zero-CoS reading with perfective tenses is only available for causatives with such a sublexical component (what I call defeasible causatives, see e.g., Fr. soigner).

(31) [vp soigner $y] \leadsto \lambda e\left[\right.$ theme $(e, y) \wedge \square_{\text {causal_success }} \exists e^{\prime}\left(\right.$ cause $\left(e, e^{\prime}\right) \wedge$ get-healthy $\left(e^{\prime}\right) \wedge$ theme $\left.\left.\left(e^{\prime}, y\right)\right)\right]$

The modal base is kept constant in both the agentive and nonagentive uses, and contains all 'causally successful' worlds. ${ }^{16}$

\section{Applying the proposal to the data}

In this section, I show how the proposal spelled-out in the previous sections can account for the data presented in the introduction. Let us begin with (5).

$$
\begin{aligned}
& \text { Dr Li m'a soigné, mais je n'ai pas guéri du tout. } \\
& \mathrm{dr} \mathrm{Li} \text { me=has treated but I NEG=have NEG cured at all } \\
& \text { 'Dr. Li treated me, but I didn't get cured at all.' }
\end{aligned}
$$

The doctor's diagnosis consists, in part, in building a set of Sqn conditions for the treatment to develop into my recovery, i.e., Sqn('I-get $\emptyset$-healthy')(e). In order for the

15 Of course, when a defeasible causative is used in the progressive, there are two sources of modality at play, and more has to be said about the way they work together in this case.

In languages like Hindi, whose SV perfective is analyzed by Altshuler 2014 as a partitive operator (yielding an incomplete event as output), the outer aspect can be responsible for switching the $\mathrm{CoS}$ in modal worlds for perfective sentences, too.

16 Contra Martin \& Schäfer (2012), who capture the contrast between the agentive vs. nonagentive use of defeasible causatives through the choice of the modal base, which, as Piñón (2014) argues, obliges them to assume that these verbs are lexically ambiguous. 
doctor to properly treat me rather than trying to do so, the doctor must know that the treatment administered realizes significantly more Sqn properties for it to culminate in the 'I-get $\emptyset$-healthy' alternative than in the ' $\neg$ I-get $\emptyset$-healthy' one. ${ }^{17}$ Therefore, the doctor's treatment $e_{S}$ has a facet $\mathscr{F}$ indicative of the right outcome, and this subset $\mathscr{F}$ of all the properties of $e_{S}$ is accessible at least under the doctor's perspective $\pi$. Since $e_{S}$ can fulfill the indicative (and sustaining) conditions on its own, (5) is acceptable under zero-CoS reading. Let us now turn to (7).

$$
\begin{aligned}
& \text { Ce traitement placebo a soigné Ana, \#mais elle n'a } \\
& \text { this placebo treatment has treated Ana but she NEG=has } \\
& \text { pas guéri du tout. } \\
& \text { NEG cured at all } \\
& \text { 'This placebo treatment treated Ana, but she didn't recover at all.' }
\end{aligned}
$$

Given the very nature of placebo treatments, the ongoing treating event has no property indicative of the right alternative: By definition, this kind of treatment does not do anything on its own, and therefore cannot actualize by itself more Sqn conditions for $e_{S}$ to develop into the 'I-get $\emptyset$-healthy' alternative than for it to develop into the ' $\neg$ I-get $\emptyset$-healthy' one. ${ }^{18}$

As for (32), native speakers asked to build a natural context for it either propose that (i) the stay is an unexpected cause for the recovery, or (ii) that the stay only facilitates the causal role of another causally necessary but insufficient condition (e.g., Ana's predisposition to recover by herself in the appropriate environment).

$$
\begin{aligned}
& \text { Ce séjour chez sa soeur a soigné Ana. } \\
& \text { this stay at her sister has treated Ana } \\
& \text { 'This stay at her sister's treated Ana.' }
\end{aligned}
$$

These natural interpretations of (32) make the zero-CoS reading problematic (see (6)), because they enter into conflict with the requirement of indicativity. Under (i), the stay has no property indicative of the recovery which is epistemically accessible before the stay triggered its curing effect (since it is explicitly said to be an unexpected cause for it); under (ii), the stay does not indicate the recovery by itself only a larger event including a causation event different from the stay could do so.

It is nevertheless possible to save (6) by some contextual means:

17 If not (if I am a desperate case or if Dr. Li is a charlatan), (5) is simply false: in this context, the verb soigner does not properly describe Dr. Li's action even when used under the zero-CoS reading (essayer de soigner 'try to treat' should be used instead).

18 Of course, it might be that an event larger than $e_{S}$ (e.g., the placebo together with some psychological reaction to it) $i$ indicative of Ana's recovery. However, in order for the zero-CoS reading to be acceptable, the event $e_{S}$ must be indicative of the result on its own. 
Explaining the link between agentivity and non-culminating causation

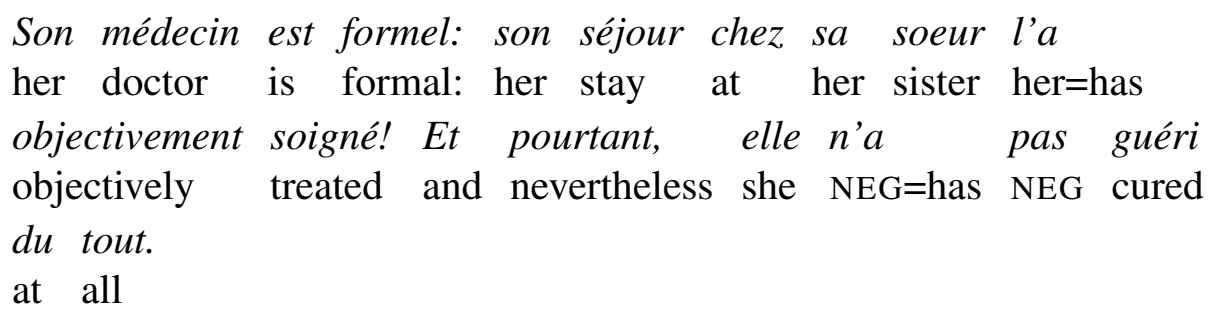

'Her doctor is absolutely certain: Her stay at her sister's objectively 'treated' her! And nevertheless, she didn't recover at all.'

I propose that adverbials like objectivement 'objectively' are 'markers of indicativity': In (33), this adverbial goes against the default interpretation in that it suggests that the stay has an indicative property by itself (before it gets efficacious). ${ }^{19} \mathrm{Be}-$ sides, the evidential clause makes clear that this indicative link is accessible from the perspective $\pi$ of the doctor.

\section{Conclusion}

This paper offers an account for why, cross-linguistically, zero-CoS readings of causative verbs are easier to get with agent than with causer subjects. It does so essentially by extending the theory of the progressive developed in Varasdi (2014a,b) to non-culminating readings of causative verbs, not only in progressive but also in perfective sentences. Under the assumption that a partial $\mathrm{CoS}$ is indicative of the whole $\mathrm{CoS}$ with respect to the contrast set, it also explains why agentivity does not play such a crucial role for the partial-CoS reading of causatives. The only additional ingredients of my account are two claims about the difference between agentive vs. nonagentive ongoing causation events: The former, but not the latter, are systematically indicative and ontologically independent of their potential effects.

\section{References}

Alexiadou, Artemis \& Florian Schäfer. 2006. Instrument subjects are agents or causers. In Donald Baumer, David Montero \& Michael Scanlon (eds.), West Coast Conference on Formal Linguistics (WCCFL) 25, 40-48. Somerville, MA: Cascadilla Proceedings Project.

Altshuler, Daniel. 2014. A typology of partitive operators. Natural Language and Linguistic Theory 32. 735-775.

19 Adding an adverbial of this kind to Mittwoch's example (17) also increases its acceptability, which is expected if it suggests indicativity. That adverbials like e.g., objectively, clearly help to get the zero-CoS reading of defeasible causatives with a causer subject was already observed by Martin \& Schäfer (2012), but this effect was not traced to indicativity. 
Asher, Nicholas. 1992. A default, truth conditional semantics for the progressive. Linguistics and Philosophy 15. 463-508.

Bertinetto, Pier Marco. 2000. The progressive in Romance, as compared with English. In Östen Dahl (ed.), Tense and Aspect in the Languages of Europe, 559-604. Berlin: Mouton - De Gruyter.

Bonomi, Andrea. 1999. The progressive and the structure of events. Journal of Semantics 14. 173-205.

Condoravdi, Cleo. 2009. Measurement and intensionality in the semantics of the progressive. Hand-out for the 5th Workshop on Discourse Structure in honor of Carlota Smith, University of Texas at Austin.

Copley, Bridget \& Phil Wolff. 2014. Theories of causation should inform linguistic theory and vice versa. In Bridget Copley \& Fabienne Martin (eds.), Causation in Grammatical Structures, 11-57. Oxford: Oxford University Press.

Demirdache, Hamida \& Fabienne Martin. 2015. Agent control over non-culminating events. In Elisa Barrajón López, José Luis Cifuentes Honrubia \& Susana Rodríguez Rosique (eds.), Verbal Classes and Aspect, 185-217. Amsterdam: Benjamins.

Dowty, David. 1977. Toward a semantic analysis of verb aspect and the English 'imperfective' progressive. Linguistics and Philosophy 1/1. 45-77.

Dowty, David. 1979. Word Meaning and Montague Grammar. Dordrecht: Reidel. Gendler Szabó, Zoltán. 2004. On the progressive and the perfective. Noûs 38. 29-59. Gerdts, Donna. 2008. Halkomelem limited control constructions. Spring 2008 Colloquium Series, Department of Linguistics, UBC.

Grano, Thomas. 2011. Mental action and event structure in the semantics of 'try'. In Neil Ashton, Anca Chereches \& David Lutz (eds.), Semantic \& Linguistic Theory (SALT) 21, vol. 21, 426-443.

Gyarmathy, Zsófia. 2015. Achievements, Durativity and Scales. Doctoral dissertation, Universität Düsseldorf.

Hacquard, Valentine. 2006. Aspects of Modality. PhD Thesis, MIT.

Haï, Isabelle. 1989. Telling 'tell'. Manuscript, Université du Québec à Montréal. Jacobs, Peter. 2011. Control in Skwwxwú7mesh. PhD Thesis, University of British Columbia.

Karttunen, Lauri. 1971. Implicative verbs. Language 47. 340-358.

Kato, Atsuhiko. 2014. Event cancellation in Burmese. Paper presented to the 24th Meeting of the Southeast Asian Linguistics Society, Yangon.

Koenig, Jean-Pierre \& Anthony Davis. 2001. Sublexical modality and the structure of lexical semantic representations. Linguistics and Philosophy 24(1). 71-124.

Levin, Beth \& Malka Rappaport Hovav. 2014. Manner and result: The view from clean. In Rob Pensalfini, Myfany Turpink \& Diana Guillemin (eds.), Language Description Informed by Theory, 337-358. Amsterdam: Benjamins. 
Explaining the link between agentivity and non-culminating causation

Liu, Jinhong. In prep. The Acquisition of Accomplishment Verbs by Mandarin Speaking Children. Doctoral Dissertation, Université de Nantes.

Martin, Fabienne. 2005. Les deux lectures de faillir+inf. et les verbes présupposant l'existence d'un événement. In Hava Bat-Zeev Shyldkrot \& Nicole Le Querler (eds.), Les périphrases verbales, 455-473. Amsterdam: Benjamins.

Martin, Fabienne \& Florian Schäfer. 2012. The modality of 'offer' and other defeasible causatives. In Nathan Arnett \& Ryan Bennett (eds.), West Coast Conference on Formal Linguistics (WCCFL) 30, 248-258. Somerville, MA: Cascadilla Press.

Martin, Fabienne \& Florian Schäfer. To appear. Sublexical modality in defeasible causative verbs. In Ana Arregui, Maria-Luisa Romero \& Andres Salanova (eds.), Modality across Syntactic Categories, Oxford: Oxford University Press.

Mittwoch, Anita. 1988. Aspects of English aspect: On the interaction of perfect, progressive and durational phrases. Linguistics and Philosophy 11/2. 203-254.

Naumann, Ralf \& Christopher Piñón. 1997. Decomposing the progressive. In Paul Dekker, Martin Stokhof \& Yde Venema (eds.), Amsterdam Colloquium 11, 241-246. Amsterdam: ITLI, University of Amsterdam.

Oehrle, Richard. 1976. The Grammatical Status of the English Dative Alternation. $\mathrm{PhD}$ Thesis, MIT.

Piñón, Christopher. 1997. Achievements in an event semantics. In Aaron Lawson \& Eun Cho (eds.), Semantics \& Linguistic Theory (SALT) 7, 273-296. Ithaca, New-York: CLC Publications, Cornell University.

Piñón, Christopher. 2014. Reconsidering defeasible causative verbs. Talk to the workshop Agent control over non-culminating events, Chronos 11, Pisa, June 2014.

Pustejovsky, James. 1995. The Generative Lexicon. Cambridge, MA: MIT Press.

Rappaport Hovav, Malka \& Beth Levin. 2008. Reflections on Manner/Result Complementarity. In Edit Doron, Malka Rappaport Hovav \& Ivy Sichel (eds.), Syntax, Lexical Semantics, and Event Structure, 21-38. Oxford University Press: Oxford.

Ruwet, Nicolas. 1995. Les verbes de sentiments peuvent-ils être agentifs? Langue française 105. 29-39.

Ryle, Gilbert. 1949. The Concept of Mind. London: Hutchinson.

Strzalko, Jaroslaw, Jan Grabski, Andrzej Stefanski, Przemyslaw Perlikowski \& Tomasz Kapitaniak. 2008. Dynamics of coin tossing is predictable. Physics Reports 469. 59-92.

Tatevosov, Sergei \& Mihail Ivanov. 2009. Event structure of non-culminating accomplishments. In Helen de Hoop Hogeweg, Lotte \& Andrej Malchukov (eds.), Cross-linguistic Semantics of Tense, Aspect, and Modality, 83-130. The Hague: Benjamins. 
Travis, Lisa. 2010. Inner Aspect. The Articulation of VP. Amsterdam: Springer.

Truswell, Robert. 2011a. Agentivity, aspectual classes, and the progressive. Manuscript, Edinburgh University.

Truswell, Robert. 2011b. Events, Phrases and Questions. Oxford: Oxford University Press.

Tsujimura, Natsuko. 2003. Event cancellation and telicity. In Japanese/Korean Linguistics 12, 388-399.

Varasdi, Károly. 2014a. A contrastivist theory of the progressive aspect. Manuscript, Universität Düsseldorf.

Varasdi, Károly. 2014b. Making progressives: Necessary conditions are sufficient. Journal of Semantics 31. 179-207.

Vecchiato, Antonella. 2004. On intentional causation in Italian. In Julie Auger, Clancy Clements \& Barbara Vance (eds.), Contemporary Approaches to Romance Linguistics. Selected Papers from the 33rd Linguistic Symposium on Romance Languages (LSRL), 343-360. John Benjamins.

Fabienne Martin

Institut für Linguistik/ Romanistik

SFB 732

Universität Stuttgart

Keplerstraße 17

70197 Stuttgart

fabienne.martin@ling.uni-stuttgart.de 